\title{
A BIENAL DE SÃO PAULO, O DEBATE ARTÍSTICO DOS ANOS I 950 E A CONSTITUIÇÃO DO PRIMEIRO MUSEU DE ARTE MODERNA DO BRASIL
}

\author{
Prof $^{a} D^{a}$ Ana Gonçalves Magalhães
}

\section{RESUMO:}

A partir da primeira etapa da pesquisa em andamento sobre as obras incorporadas ao acervo do antigo Museu de Arte Moderna de São Paulo (MAM) - hoje no acervo do Museo de Arte Contemporânea da Universidade de São Paulo (MAC USP), que resultou na exposição Um Outro Acervo do MAC USP: Prêmios-aquisição da Bienal de São Paulo, 195I-I963 (MAC USP, 20I2-20I3), procuramos reavaliar algumas premissas adotadas pela historiografia da arte no Brasil na análise da premiação de aquisição e seu papel na constituição de um acervo internacional de arte moderna para $\circ$ país. Tais aspectos nos levaram a revisar a dimensão do debate em torno das experiências de abstração nos anos 1950, o sistema de seleção das obras para a premiação (que sugere um engajamento muito próximo com o contexto internacional), a constituição de um sistema internacional de circulação de artistas e de obras, dentre outras questões.

\section{PALAVRAS-CHAVE:}

Bienal de São Paulo, Museu de Arte Moderna de São Paulo, Colecionismo, Arte Moderna

\begin{abstract}
:
Taking the exhibition Another Collection of MAC USP: Acquisition Prizes of the Bienal de São Paulo, 195I-1963 (MAC USP, 2012-2013) as a framework, we have searched to analyse the set of works gathered for the collection of the former São Paulo Museum of Modern Art (MAM) by means of the acquisition prizes of the Bienal de São Paulo in the 1950s, today belonging to MAC USP.We thus proposed to revaluate some of the premises adopted by art historiography in Brazil in regard to the acquisition prize system of the São Paulo Biennial, and its role in the making of an international modern art collection among us. Such aspects led us to revise the dimension of the abstraction debate in the 1950s, the system of selection of works suggesting a strong engagement of local art criticism with the international context, the making of an international system of circulation of artists and works, among others.
\end{abstract}

\section{KEYWORDS:}

Bienal de São Paulo, São Paulo Museum of Modern Art, Collectionism, Modern Art

I Museu de Arte Contemporânea da Universidade de São Paulo. 
Mas a Bienal - pelo menos para o Brasil -

é um pequeno mundo ao qual será sempre

preciso retornar, para descobrir roteiros novos e paisagens e formas talvez inéditas.

Murilo Mendes, “Sugestões da Bienal”, Diário Carioca, 02//2/|95 I

O MAC USP possui um conjunto significativo de obras oriundas do ambiente da Bienal de São Paulo'. As obras exibidas na Bienal de São Paulo que - Museu abriga já foram expostas algumas vezes, nas três últimas décadas, para ilustrar a história do evento ${ }^{2}$. Mas ainda ainda estamos por refletir sobre essas obras enquanto acervo de museu. Nesse sentido, a historiografia que se constituiu até então deverá ser reavaliada, sobretudo no que diz respeito à maneira como a premiação de aquisição foi tratada até agora e qual a percepção que se formou sobre esse conjunto. Não há, até o presente momento, um estudo sistemático sobre o sistema de premiação da Bienal de São Paulo, que além de ter sido objeto de uma exposição em $2012^{3}$, nos levou a assumir algumas premissas que, de fato, aos poucos foram sendo desconstruídas pela documentação pertinente 4 . Em primeiro lugar, temos de reavaliar a premissa de que a premiação de aquisição era feita sem nenhum critério - ou sem um critério claro, discutido e estabelecido pelo corpo qualificado de críticos e diretores artísticos em torno do antigo MAM. Isto é, de que as obras escolhidas dentro dessa chave refletiriam, assim, o gosto pessoal dos patronos que haviam contribuído para sua aquisição. Esta premissa determina a segunda: de que as obras reunidas dessa forma constituíram um acervo de "segunda ordem", e menos relevante ou menos representativo no entendimento de uma narrativa de arte moderna, para o primeiro museu brasileiro dedicado à arte moderna.

Muito já se escreveu sobre as edições da Bienal do período, ressaltando seu caráter didático, o quanto contribuíram para a formação de um público para a apreciação da arte moderna no Brasil, e na consolidação de uma história da arte moderna internacional da qual o meio artístico brasileiro fazia parte ${ }^{5}$.

I Falar do "ambiente da Bienal de São Paulo" significa considerar a relação do acervo do Museu com mostras de tipo Bienal num recorte mais amplo, contemplando obras e artistas que participaram das edições da Bienal de Veneza, no mesmo período que analisamos aqui (195I a 1963).

2 Cf. Prêmios da Bienal de São Paulo. São Paulo: MAC USP, 1985. Pela primeira vez, com esse volume e a exposição que ele documentava, o MAC USP fazia o levantamento sistemático das obras em seu acervo, premiadas nas edições da Bienal de São Paulo até aquele momento, mas sem fazer a distinção entre a premiação regulamentar e a premiação de aquisição, que é um dos pontos a ser tratado neste artigo. Tal lista serve, até hoje, de referência para qualquer pesquisador que queira estudar essas obras.

3 Veja-se exposição Um outro acervo do MAC USP: Prêmios-aquisição da Bienal de São Paulo, 195 I-1963, MAC USP, de 25 de agosto de 2012 a 28 de julho de 2013, com curadoria da autora. Disponível no site: http://www.mac.usp.br/mac/EXPOSI\%E7oes/2012/outroacervo/index.htm.

4 Para a exposição, fizemos o levantamento da documentação pertinente nos dossiês de artistas e no fundo histórico do Arquivo Histórico Wanda Svevo, Fundação Bienal de São Paulo.Ao mesmo tempo, esta foi cotejada com as pastas dos artistas da Seção de Catalogação do MAC USP.Além disso, o conjunto documental foi confrontado com os catálogos das edições da Bienal entre 195I e 1963.

5 Optamos por indicar apenas alguns poucos títulos mais recentes que constituem essa literatura na referência bibliográfica ao final do texto. Observamos que quando se escreveram histórias da Bienal de São Paulo, estas percorrem toda a trajetória da instituição até os dias atuais. Por outro lado, há uma farta literatura sobre a presença de artistas e grupos de artistas que participaram na Bienal de São Paulo e sua relação e impacto no meio artístico brasileiro. Mais recentemente, surgiu uma literatura internacional, muitas vezes encomendada pelos órgãos diplomáticos e/ou governamentais que se ocuparam dos pavilhões de seus países nas edições da Bienal paulistana, mas que procura dar conta das participações dos artistas de seus países. O caso mais recente é o do volume organizado por Ulrike Gros e Sebastian 
Entretanto, ainda está por ser feita uma reflexão sobre o papel do evento na constituição do acervo mais relevante de arte moderna que o País tem. Tomamos o ambiente da Bienal de São Paulo, qual seja, esta moldura através da qual estruturou-se um sistema internacional de arte, para fazermos alguns apontamentos sobre o papel sobretudo deste acervo estrangeiro na constituição de uma narrativa de arte moderna para nós. Considerando-se ainda os novos estudos em história da arte, que apontam para a revisão da história das exposições na formação das noções de arte que foram se cristalizando através da historiografia, bem como o fenômeno da globalização e seus reflexos no campo da arte, a Bienal de São Paulo e a formação do acervo do antigo MAM são temas privilegiados para contribuirmos nessas direções. Estamos diante de duas instituições históricas, que tem sido vistas à luz de acontecimentos da última década, marcada pelo boom de mostras sazonais ${ }^{6}$. Mas principalmente ao falarmos da Bienal de São Paulo, ela estaria ligada à era "pré-global”, em que a linguagem artística modernista começou a ser divulgada como um valor da cultura das sociedades ocidentais, naquele instante entendida como universal.

Nas duas últimas décadas e diante da intensificação das políticas multiculturalistas, apoiadas pela Organização das Nações Unidas (ONU), tratadas a partir das teorias do pós-colonialismo, a experiência da Bienal de São Paulo e, principalmente, sua importância na formação do primeiro acervo modernista internacional do Brasil, torna-se um estudo de caso fundamental. Não só porque essas instituições, aqui, haviam saído do centro pela primeira vez, mas porque isto se deu e só foi possível graças ao papel desempenhado pelo País no contexto maior da Guerra Fria. Nos anos 1950, assim como na última década, o Brasil apresentava condições sócio-político-econômicas favoráveis à implantação de uma economia da arte, para contrabalançar as grandes perdas, principalmente do território europeu, com a II Guerra Mundial. Por outro lado, no momento de instauração das instituições de arte moderna entre nós, o País emergia como grande aliado da política externa norte-americana, de hegemonia sobre o continente latino-americano, entendido assim em bloco por conta das ambições da nova potência econômica em que se transformava os Estados Unidos no mundo.

Esse contexto, por si só, já é instigante e inovador para os estudos de história da arte que vem sendo desenvolvidos atualmente. Além disso, no que concerne a noção mesma de arte moderna, o conjunto de obras reunidas dentro dessa moldura, também nos coloca novos problemas de como tratar a pertinên-

Preuss. Cf. Ulrike Groos \& Sebastien Preuss (org.). German Art in São Paulo. Ostfildern: Institut für Auslandsbeziungen/Hatje Cantz, 2013, para o qual contribuímos com um texto sobre as obras alemãs dos anos 1950 que permaneceram conosco.

6 No artigo de autoria de Ivo Mesquita para a Revista USP (Cf. Revista USP. Cinquenta anos de Bienal Internacional de São Paulo, São Paulo, n.52, dezembro/fevereiro 200I-2002, pp. 72-77, disponível on-line através do link: http://www.usp.br/revistausp/52/SUMARIO-52.htm), o autor falava em 40 bienais em funcionamento no mundo (p. 74). Na pesquisa feita pela equipe de produção da Bienal de São Paulo em sua edição de 2008, curada por Mesquita, computaram-se 250 bienais ao redor do mundo. Isto é, no intervalo de menos de uma década, esse modelo de exposição multiplicou-se por seis, num período em que curiosamente se começou a falar na sua crise.

$\mathrm{Na}$ atual bibliografia sobre o assunto, tem-se utilizado a nomenclatura "mostra sazonal" para falar deste gênero de exposição, que tem um periodicidade pré-determinada, mas que pode variar de 2 (Bienal de São Paulo, Bienal de Veneza, Bienal de Havana, etc), 3 (Trienal de Yokohama, por exemplo), 4 (Quadrienal de Roma), 5 (Documenta de Kassel, Manifesta) até 10 anos (Skulpturprojekte de Münster,Alemanha). 
cia de uma narrativa-mestre da $\operatorname{arte}^{7}$. Se, de um lado, tal acervo não corresponde a uma narrativa de arte moderna consolidada através dos manuais de história da arte - que trabalham com os grandes nomes, com a noção de obra-prima e com a experiência vanguardista para constituir a definição de arte moderna por excelência -, por outro, ele apresenta uma configuração datada, e por isso mesmo, de grande interesse para a revisão da historiografia da arte moderna. Ou seja, o fato dele ter sido um acervo constituído dentro das Bienais de São Paulo, torna-o passível de ser visto como uma camada histórico-arqueológica, se assim podemos dizer, de um determinado tempo - no qual ainda se trabalhava com uma narrativa de arte moderna em aberto, cuja cristalização final só veio com os escritos que a sistematizaram no final da década de 1950, dentro e fora do Brasil| $^{8}$.Assim, levantamos aqui alguns elementos para a reavaliação do papel que o sistema de premiação dos eventos Bienal teve na constituição desse acervo, e o que estava em jogo quando se falava de arte moderna naquele momento.

\section{****}

Ao receber o acervo do antigo Museu de Arte Moderna de São Paulo (MAM), em 1963, a Universidade de São Paulo, por via de seu recém-criado Museu de Arte Contemporânea (MAC) passou a cuidar das coleções mais importantes de arte moderna do País.Além de ter sido o primeiro museu de arte moderna da América do Sul, o antigo MAM havia sido o organizador da segunda exposição de tipo Bienal do mundo, em 195I. Inspirada no modelo de seu equivalente italiano, a Bienal de Veneza ${ }^{9}$, a versão paulista veio para colocar São Paulo no circuito artístico internacional. Nas palavras do então diretor artístico Lourival Gomes Machado ${ }^{10}$ :

Por sua própria definição, a Bienal deveria cumprir duas tarefas principais: colocar a arte moderna do Brasil, não em simples confronto, mas em vivo contato com a arte do resto do mundo, ao mesmo tempo que para São Paulo se buscaria conquistar a posição de centro artístico mundial.

7 Usamos aqui uma expressão adotada por Hans Belting, por exemplo, analisando aquilo que ele chama de "arte global". Cf. Hans Belting, "Contemporary art as global art: a critical estimate" In: Hans Belting \& Andrea Buddensieg (orgs.). The Global Art World. Audiences, Markets, and Museums. Ostfildern: Hatje Cantz, 2009, pp. 38-73, onde ele fala em "master narrative of art".

8 Para citar apenas dois desses manuais, que até hoje têm enorme influência na formação em história da arte, sobretudo entre nós, devemos lembrar que o famoso livro do crítico britânico Herbert Read sobre a história da pintura moderna - seguido de uma história da escultura moderna - foi originalmente publicado em 1959. Onze anos depois, Giulio Carlo Argan publicava seu Arte Moderna (Cf. Herbert Read, A Concise History of Modern Painting. Londres:Thames \& Hudson, 1959 e Giulio Carlo Argan, L'Arte Moderna: Dall'Illuminismo ai Movimenti Contemporanei. Florença: Sansoni Editori, 1970). Ao mesmo tempo, esses autores tão relevantes participaram em diferentes momentos no júri de premiação regulamentar da Bienal de São Paulo, ao longo dos anos 1950. Read foi, inclusive, comissário da representação nacional britânica, naqueles anos.

9 Fundada em 1893, mas tendo se realizado pela primeira vez em 1895, a Bienal de Veneza foi a primeira mostra do gênero, ao criar um evento de arte nos moldes dos que eram realizados dentro das grandes exposições universais do século XIX, mas dissociando-o dos feitos da indústria e da tecnologia. Cf. Bruce Altshuler. Salon to Biennial. Exhibitions that Made Art History, I863-1959 (Vol. I). Londres: Phaidon Press, 2008. A Bienal de Veneza só viria a se transformar em uma exposição internacional de arte, com convite às participações estrangeiras, a partir de 1908. Seu primeiro objetivo era o de apresentar a produção das diferentes regiões da Itália, com o intuito de consolidar o processo de unificação do país, que havia se iniciado em I86I.

10 Lourival Gomes Machado, apresentação In: I Bienal do Museu de Arte Moderna de São Paulo, outubro a novembro de 195I. São Paulo: Museu de Arte Moderna de São Paulo, I 95 I (vol. I), p. I5. 
Gomes Machado falava ainda em "certame artístico internacional”. Isto significava que a apresentação das obras era submetida a uma seleção feita por um júri de críticos, que naquele momento pautavam suas escolhas por aquilo que consideravam ser as poéticas e práticas da arte moderna - entendida naquele contexto como arte da atualidade -, por sua vez interpretadas dentro de categorias de suporte (ou medium) precisas: pintura, escultura e gravura. Para a seleção dos brasileiros, para o que seu diretor artístico chamava de "seção geral", um time de críticos brasileiros havia sido convocado para analisar os trabalhos enviados. A seção geral era então complementada por salas especiais, dedicadas aos grandes nomes do modernismo brasileiro, que segundo Gomes Machado, se alternariam nas edições vindouras"'. No caso das 21 delegações estrangeiras que participaram da I Bienal, o convite era feito aos órgãos diplomáticos competentes que apresentavam sua seleção dentro das categorias previstas. Entretanto, e desde sua primeira edição, um aspecto importante marcaria a formatação das representações estrangeiras na Bienal paulistana. Nos preparativos da viagem que Yolanda Penteado empreendeu à Europa para apresentar o projeto da I Bienal aos órgãos diplomáticos da França, da Bélgica, da Holanda, da Inglaterra, e de outros países previstos em seu roteiro, Gomes Machado preparara um documento orientando-a na negociação com os países a fazer demandas específicas para o Brasil ${ }^{12}$. Uma delas, que só viria a se efetivar mais para frente, era a organização de uma sala especial dedicada a Vincent van Gogh como representação nacional holandesa. Isso se repetiria nas demais edições, em que os diretores artísticos do antigo MAM negociaram salas especiais sobre as correntes vanguardistas mais importantes do início do século $X X$, constituindo para São Paulo algo que se consolidaria mais tarde em seus núcleos históricos. Sabemos hoje que tal preocupação - em princípio ligada à formação de um público para arte moderna no Brasil, questão frequentemente levantada pelos críticos modernistas $^{13}$ - não era só local. A Bienal de Veneza, ao retomar suas atividades no imediato pós-II Guerra, em 1948, passou a dedicar salas especiais de revisão e apresentação dos principais movimentos e correntes modernistas que eram entendidos como precursores e parte constituinte da história da arte moderna, tais como as salas do impressionismo na França, do pontilhismo francês e do divisionismo italiano, do expressionismo, etc. Tratava-se também de restabelecer a conexão da Itália com o ambiente internacional, depois dos duros anos do Fascismo, sobretudo depois da aliança com a Alemanha nazista, entre 1937 e 1943. Nesse mesmo contexto, surgiria ainda a Documenta de Kassel, em 1955, que procurou redimir a Alemanha de seu passado recente de condenação da arte moderna, nas suas formas vanguardistas, que havia motivado a Exposição

I I Em sua primeira edição, a Bienal de São Paulo contemplava salas especiais de Cândido Portinari,Victor Brecheret, Lasar Segall, Livio Abramo, Oswaldo Goeldi, Maria Martins, Bruno Giorgi e Emiliano di Cavalcanti. Nas edições seguintes, apareceriam outros artistas importantes para a história do modernismo brasileiro, tais como Anita Malfatti, Paulo Rossi Osir,Tarsila do Amaral e Flávio de Carvalho.

12 Veja-se carta de Lourival Gomes Machado a Yolanda Penteado, 8 de março de 195I, em papel timbrado do Museu de Arte Moderna de São Paulo, FMS_0023-0I, Fundo Francisco Matarazzo Sobrinho, Arquivo Histórico Wanda Svevo, Fundação Bienal de São Paulo.

13 Veja-se, por exemplo, os escritos de Sérgio Milliet, ainda na década de 1940. A historiografia brasileira entende que um dos marcos da sua direção artística à frente do antigo MAM e da Bienal de São Paulo, entre 1953 e 1957, é justamente uma sequência de mostras das vanguardas históricas no contexto das delegações estrangeiras participantes da Bienal, tais como a sala especial dedicada a Picasso e ao Cubismo pela delegação francesa de 1953; na mesma edição, uma revisão do Futurismo pela representação nacional italiana; e na edição de 1955, a sala especial que a Alemanha dedicou à apresentação dos mestres da Bauhaus. 
de Arte Degenerada em 1937 e resultado na destruição e dissolução em massa dos acervos de arte moderna daquele país.

Entretanto, o tom didático da direção artística da segunda, terceira e quarta edições da Bienal de São Paulo por Sérgio Milliet, era lido por seus pares locais como ligado a um projeto de constituição de um acervo de arte moderna para São Paulo. É muito sintomático, por exemplo, que alguém tão próxima ao crítico paulista, como a também crítica Maria Eugênia Franco, comparasse a II Bienal a uma visita a um museu de arte moderna ${ }^{14}$ :

(...); do ponto de vista local, deu aos brasileiros uma possibilidade única de formarem uma cultura estética de arte moderna, desde que favoreceu suas duas bases essenciais:a visual e a histórica. Temos ouvido dizer, muitas vezes, que a exposição do lbirapuera vale por uma viagem pelos museus de arte moderna do mundo. A II Bienal equivale, sem dúvida, a uma viagem ideal pela história da arte moderna, pois dificilmente encontraríamos, reunidas, obras de tanta importância no processo de evolução da arte contemporânea.

(...)

Na sua parte positiva, poderíamos dizer que o plano da II Bienal, é um plano de professor de história da arte, procurando mostrar as raízes da arte moderna atual, a partir de seu momento mais agudo de ruptura, isto é, a partir do momento em que, apresentando-se como uma reação mais violenta à reação primeira, o expressionismo e o cubismo se contrapõem ao impressionismo. [grifos meus]

Franco, ademais, fala não só na formação de um público para arte moderna, na II Bienal como espaço equivalente a um museu de arte, mas também na preocupação de formulação de uma narrativa de arte moderna, quando sugere que seu plano é de "um professor de história da arte". Esse plano, que afinal unia produção recente e histórica da primeira metade do século $X X$, articulada numa narrativa e que se aproximava ao museu de arte moderna, foi de certo modo cristalizado através dos prêmios-aquisição da Bienal paulista.

Assim como na Bienal veneziana, havia dois tipos de premiação na Bienal de São Paulo enquanto evento organizado pelo antigo MAM: os prêmios regulamentares e os prêmios-aquisição ${ }^{15}$. $O$ primeiro tipo de premiação era dado nas categorias de pintura, escultura e gravura, dividindo-se entre premiação estrangeira e premiação brasileira.Através dela, costumava-se celebrar o conjunto da obra apresentado pelo artista premiado. Segundo seu regulamento, não era compulsório que o artista doasse o conjunto ou uma obra do conjunto premiado para o antigo MAM, ainda que muitos dos premiados tenham doado pelo menos uma obra ao Museu, nesses casos.

I4 Maria Eugênia Franco, "Importância educativa da exposição", Reportagem I da série "Panorama da 2a. Bienal", Última Hora, Io. de fevereiro de 1954. A imagem da II Bienal como "uma viagem pelos museus de arte moderna do mundo", naquele contexto, é muito forte, uma vez que esse tipo de instituição de fato ganhou força naqueles mesmos anos, e que o museu de arte moderna ainda era uma novidade mesmo em alguns países da Europa.

I5 De fato, o modelo é o veneziano, que já em sua segunda edição em 1897, cria tal sistema de premiação para angariar um acervo de arte moderna para a cidade de Veneza - originalmente uma Galleria Internazionale d'Arte Moderna, hoje em depósito no Museu de Ca' Pesaro. 
Já os prêmios de aquisição da Bienal de São Paulo eram de fato pensados para compor o acervo do antigo MAM. Partia-se de um sistema de mecenato, em que a direção do Museu convidava empresários, associações, colecionadores importantes a contribuir com uma quantia em dinheiro para que se comprasse uma obra ou um conjunto de obras para o Museu ${ }^{16}$. Em alguns casos, eram os órgãos diplomáticos dos países participantes da Bienal que intermediavam essas aquisições ou as realizavam. Ao contrário da premiação regulamentar, os prêmios-aquisição da Bienal de São Paulo tinham assim um sentido mais claro de permanência.

Além disso, os prêmios-aquisição pareciam continuar a obedecer as categorias da premiação regulamentar, ou seja, comprava-se para o antigo MAM obras representativas da pintura, da escultura e da gravura modernas, com algumas poucas exceções ${ }^{17}$.

Percebemos ainda uma presença bastante significativa de obras em papel. Na história da formação do acervo do antigo MAM e sua continuação no MAC USP, o conjunto de obras em papel compõe quase dois terços do total de obras do acervo. No contexto do antigo MAM, elas eram catalogadas dentro da categoria de gravura, ainda que fossem desenhos, guaches, aquarelas ou colagens, obedecendo a uma lógica descritiva dos suportes da arte moderna, que no ambiente das grandes mostras internacionais e dos departamentos dos museus-modelo de arte moderna do mundo ainda parecia pensar em categorias tradicionais. A noção dada pelo termo em inglês prints and drawings (literalmente, gravuras e desenhos), muito corrente no período, foi o que prevaleceu para nós também. Mas ele esconde a riqueza de técnicas de impressão empregadas no período pelos artistas modernistas. Naquele momento, havia uma forte experimentação com as técnicas tradicionais de gravura, aliadas a técnicas reprográficas, ao uso de novos equipamentos gráficos e de larga tiragem, que levaram à elaboração de proposições únicas pelos artistas do período. Mencionamos aqui dois exemplos, sendo o primeiro deles o belo conjunto de gravuras a buril de Henri-Georges Adam, adquiridos graças ao patrocínio da indústria de cristais Prado, na II Bienal de São Paulo ${ }^{18}$. Nesta série, Adam, ao mesmo tempo em que trabalha com uma técnica tradicional da gravura em metal, elabora suas composições com várias matrizes, como num trabalho de quebra-cabeças, no qual ele vai criando formas abstratas e figurativas. $O$ mesmo ocorre com as gravuras

16 Veja-se, por exemplo, carta de Francisco Matarazzo Sobrinho ao Rotary Club de São Paulo, em papel timbrado da Metalúrgica Matarazzo, datada de 17 de agosto de 1950, pedindo apoio da instituição para a premiação da Bienal. O mesmo conteúdo pode ser lido em carta que Matarazzo endereçou ao Presidente da Federação das Indústrias do Estado de São Paulo, também em papel timbrado da Metalúrgica Matarazzo, datada de 15 de setembro de 1950. FMS_0019-0I e FMS_0022-0I, Fundo Francisco Matarazzo Sobrinho, Arquivo Histórico Wanda Svevo, Fundação Bienal de São Paulo. Ainda que as cartas não façam menção específica à premiação de aquisição, pode-se verificar na documentação das obras incorporadas ao acervo do antigo MAM (hoje no MAC USP) através dessa categoria, a menção aos doadores empresariais e de associações de classe ou culturais. Dentro do conjunto da Federação das Indústrias do Estado de São Paulo, por exemplo, estavam empresas como a Moinho Santista, a indústria de critais Prado, a própria Metalúrgica Matarazzo, entre outros, que contribuíram para esta categoria de premiação.

17 A exemplo da tapeçaria de Émile Gilioli incorporada ao acervo do antigo MAM como prêmio-aquisição Moinho Santista, da IV Bienal de São Paulo. "Defesa da Flor” (c. 1957) figurou com um conjunto de tapeçarias modernistas na representação nacional da França na Bienal de 1957, ao lado de Le Corbusier.

18 Henri-George Adam aparecia na representação nacional da França, que em 1953 era antecedida por uma grande mostra retrospectiva de Picasso - cuja estrela era "Guernica” (1937, Museu Reina Sofía, Madri) - e com uma sala especial do Cubismo. 
de Marcel Fiorini ${ }^{19}$, adquiridas para o antigo MAM com o patrocínio da Caixa Econômica Federal na III Bienal de São Paulo, em I 955. Fiorini emprega a água-forte, o buril e a água-tinta para criar suas composições em cores, nas quais percebemos um arranjo em camadas.

Outra grande questão que se coloca diante dessas obras é o debate em torno da abstração, nos anos 1950, no Brasil e no contexto internacional. No caso brasileiro, fala-se da Bienal de São Paulo quase como uma conseqüência da mostra inaugural do antigo MAM, em 1949,"Do Figurativismo ao Abstracionismo", na qual o primeiro diretor artístico do Museu, o crítico belga Léon Dégand, encontrou séria resistência ao seu discurso em defesa de uma arte abstrata baseada na experiência dos grupos de Arte Concreta, na França dos anos 1930 - para os quais a presença de artistas como Wassily Kandinsky, Theo van Doesburg, Piet Mondrian e o uruguaio Joaquín Torres-García foram personagens fundamentais ${ }^{20}$. A historiografia da arte no Brasil privilegiou a emergência dos grupos concretistas brasileiros nos anos 1950 e procurou entender a Bienal de São Paulo em diálogo com essas vertentes. Ela exprime, assim, a inflexão desse debate, que assistiu também a retomada do modelo de escola de artes da Bauhaus, por via de um projeto como a da Hochschule für Gestaltung de Ulm (inagurada em 1955) ${ }^{21}$. Dessas vertentes, além da famoso prêmio regulamentar dado a Max Bill na I Bienal de São Paulo², há dois casos que merecem destaque. Na II Bienal, o Jockey Club de São Paulo comprou a tela "Composição no. 99" de Friedrich Vorbemberg-Gildewart (representação nacional alemã), artista cujo percurso se fez na relação com grupos como o De Stijl, Cercle et Carré, Abstraction-Création, e que seria nomeado professor da cadeira de comunicação visual da Hochschule für Gestaltung de Ulm, desde seu primeiro ano de funcionamento. Outro exemplo é o de Fritz Winter, prêmio-aquisição na III Bienal de São Paulo, com a obra "Preto Independente no Espaço", exibida com outras nove pinturas suas.Ao lado de mais quatro artistas e de uma sala especial dedicada a Max Beckmann, ele aparecia como um legítimo herdeiro da Bauhaus de Dessau. De fato, ele havia iniciado sua formação naquela escola em 1927. Com a ascensão do Nazismo, Winter entrou num período de ostracismo, que culminou com seu serviço militar na Polônia e sua prisão pelo exército russo na Sibéria. Libertado em 1949, ele retornou ao seu país no auge do "renascimento"

19 Nascido na Argélia, Fiorini estabeleceu-se em Paris em 1947, e consolidou sua carreira como artista no meio artístico daquela cidade. Participou duas vezes na Bienal de São Paulo, em 1955 e em 1973, como representante da França - com todas as contradições que isso pudesse significar, diante da violenta guerra de independência da Argélia, entre 1954 e 1962.

20 Cf. Ana Gonçalves Magalhães, "O debate crítico na Exposição do Edifício Sul América, Rio de Janeiro, 1949” In: Roberto Conduru \& Vera Beatriz Siqueira (orgs.). Anais do XXIX Colóquio do Comitê Brasileiro de História da Arte. Rio de Janeiro: Comitê Brasileiro de História da Arte / CBHA, 2009, pp. I20-I 28.

2I Para uma análise das relações culturais entre o Brasil e a Alemanha no contexto da Bienal de São Paulo e o papel desempenhado pela Hochschule für Gestaltung de Ulm nessas relações, veja-se Martina Merklinger. Die Biennale São Paulo. Kulturaustausch zwischen Brasilien und der jungen Bundesrepublik Deutschland (1949-1954). Bielefeld:Transcript Verlag, 2013, resultado de sua tese de doutorado apresentada à Universidade de Bonn.

22 Devemos lembrar que Max Bill não só foi o primeiro diretor da escola de Ulm, como arquiteto responsável por projetar os edifícios da sede da escola. Além disso, tal projeto se ergueu com recursos do braço cultural do Plano Marshall norte-americano - de resgate das economias da Europa depois da II Guerra Mundial. Para uma análise atualizada da relação de Max Bill com o Brasil, veja-se Martina Merklinger, "Konkretes im Bill-Jahr. Max Bill (1908-1994) und seine Begegnungen mit Brasilien", Martius-Staden Jahrbuch, n55, 2008. 
da arte moderna ali. No ano seguinte, recebeu prêmio da XXV Bienal de Veneza (1950). O prêmio-aquisição veio no momento em que foi nomeado professor da Academia de Belas-Artes de Kassel. Embora sejam evidentes suas referências às experiências abstratas da Bauhaus, "Preto Independente no Espaço" trabalha com aspectos materiais também importantes, tais como as manchas pretas que parecem saltar para fora da tela e se contrapõem a uma superfície composta de zonas coloridas, marcadas pela gestualidade do artista. Há certa intensidade subjetiva, menos vista nas tendências concretistas daquele momento, mas que talvez resgatem as experiências de Kandinsky e Klee com a cor na primeira fase da Bauhaus.

De fato, as experiências com a abstração que estão em pauta nos anos 1950 abrem-se para tendências muito distintas, que envolvem o embate maior da vertente concretista com o informalismo (ou tachismo), e o desdobramento de experimentações com o surrealismo e um forte interesse pela pintura dita "primitiva" (realizada por artistas autodidatas). No que diz respeito à abstração de cunho informal, o próprio Winter reflete essa tendência, na medida em que sua experiência de abstração dos anos 1950 - em que ele esteve presente na Bienal de São Paulo por três vezes - resultou da criação de seu Grupo Zen, em 1949. Originalmente conhecido como Gruppe der Ungegenständlichen (ou o Grupo dos não-objetuais), era formado por ele e outros seis artistas, dentre os quais Willi Baumeister (também presente no acervo do MAC-USP e prêmio-aquisição da I Bienal de São Paulo), e tinha por objetivo retomar as práticas e o ambiente do Cavaleiro Azul (grupo de expressionistas em torno de Kandinsky, da primeira década do século), ao mesmo tempo associando a cor à filosofia zen budista, dando origem a uma vertente de abstração não-geométrica.

Será preciso ainda investigar com maior profundidade a presença de artistas ligados aos chamados Art Clubs, e em que medida essas associações propagavam a arte concreta como um equivalente de arte abstrata ou de arte vanguardista (os termos parecem se alternar), sem que necessariamente tal linguagem fosse estritamente expressa pela geometria ${ }^{23}$. Os casos italiano e austríaco são bastante significativos para a análise dessa questão, pois muitos dos

23 Não localizamos até o momento um estudo sobre a história dos Art Clubs. Através de uma notícia de divulgação da abertura de uma exposição promovida por um dos Art Clubs italianos, em Turim, provavelmente de 1949-50, onde o artista austríaco Gustav Kurt Beck aparece numa foto com um grupo de artistas - dentre eles o italiano Felice Casorati, então presidente do Art Club de Turim - representando - Art Club fundado por ele em Viena, temos algumas informações sobre as atividades dessas associações. Veja-se recorte de material de divulgação da exposição do Art Club de Turim, s.d., Documentação Gustav Kurt Beck, Pasta I, Arquivo do Belvedere, Viena. Abaixo da fotografia, lê-se em alemão: "O Art Club, uma associação internacional dos chamados 'vanguardistas' nas artes plásticas, originou-se há poucos anos. Em quase todas os países de cultura do mundo, encontram-se seções nacionais dessas vertentes da arte." É possível também verificar-se algumas das atividades do Art Club de Roma, que ao que tudo indica, foi a primeira seção a ser criada dessa associação internacional, no imediato segundo pós-guerra. Na apresentação para o pequeno catálogo da exposição do Art Club de Roma no antigo MAM, em 1950, Waldemar Cordeiro (que assinava como vice-presidente do Art Club de São Paulo) discorria sobre uma proposta de intercâmbio de artistas através dessas associações livres de artistas no mundo. $O$ presidente, Eduardo Bizzari, dava notícias sobre o surgimento do Art Club de Roma como uma iniciativa dos artistas vanguardistas italianos, em 1945, para criar de fato um livre intercâmbio, sem intervenção de órgãos governamentais, entre artistas de vários países, defensores das formas mais radicais da arte. Cf. Catálogo Exposição do Art Club de Roma, junho/julho de 1950, Museu de Arte Moderna de São Paulo. Um elemento importante, tanto no texto de Cordeiro quanto no texto de Bizzari, é justamente o fato de tal associação ter surgido em contraposição ao um sistema "autárquico" (termo utilizado por Cordeiro), em outras palavras, os sindicatos de artistas regionais e sua versão nacional, que tinham um enorme poder sobre as instituções artísticas italianas durante a era fascista. 
artistas escolhidos para representar estes países na Bienal de São Paulo nos anos 1950, estiveram envolvidos com a criação de Art Club nacionais. A delegação austríaca, ao se reafirmar no segundo pós-guerra como nação democrática (depois dos anos de anexação à Alemanha), parece ter privilegiado artistas ligados a esse ambiente. Na segunda edição da Bienal de São Paulo, Gustav Kurt Beck e Wander Bertoni representariam a Áustria ${ }^{24}$. O primeiro, presente com um conjunto de linoleografias, foi o primeiro presidente do Art Club de Viena e em seu país esteve ligado à disseminação da arte concreta. Seu colega e parceiro de delegação da II Bienal, o escultor Wander Bertoni, também trabalhou com esculturas abstratas, das quais o antigo MAM preservou uma obra em madeira. Kurt Beck foi posteriormente convidado a fazer uma exposição individual no antigo MAM $^{25}$, e apresentou guaches e algumas pinturas, desta vez vistas de cidades ainda mais abstratizantes. De qualquer forma, seria difícil analisá-las formalmente num sentido mais estrito de arte concreta. Já a escultura de Bertoni, "Composição" (1953), parece ligar-se mais às questões da arte concreta, embora sua materialidade (a madeira) se distancie da prática de outros concretistas, que privilegiavam metais e materiais industriais.

O fato é que o conjunto que permaneceu em São Paulo, hoje no MAC USP, cobre uma experiência muito rica e nada cristalizada da ideia de abstração, além do resgate das experiências do surrealismo, de vertentes do expressionismo, das reintepretações da pintura de Picasso - dada a enorme circulação de sua "Guernica" no início dos anos $1950^{26}$ - e de Matisse, bem como da redescoberta da ideia de primitivo ${ }^{27}$. Nesse sentido, aquilo que o antigo MAM de São Paulo consolidou como acervo de arte moderna parece acompanhar os desdobramentos desse debate principalmente na França e na Itália, e em outros territórios europeus. Isso em um contexto internacional em que os Estados Unidos procuravam afirmar sua hegemonia cultural, e em que expressionismo abstrato ali apresentava-se como uma nova forma de arte moderna, cuja crítica procurou reivindicar como autenticamente norte-americana, omitindo seus vínculos com as experiências do velho continente ${ }^{28}$. No caso da Bienal de São Paulo (tal como

24 Tanto Beck quanto Bertoni pertenceram à geração que poderíamos chamar de transição da Áustria sob domínio do Nazismo e os anos 1950. De qualquer modo, e por conta do engajamento dos dois artistas na promoção da arte de vanguarda a partir do fim da II Guerra Mundial, eles aparecem como os mestres da geração que se formou nos anos 1950 na Áustria, e antes de virem para São Paulo, foram apresentados como os grandes vanguardistas de seu país no pavilhão nacional durante as edições da Bienal de Veneza. Cf Jasper Sharp (org.). Österreich und die Biennale Venedig, 1895-2013. Nuremberg:Verlag für Moderne Kunst, 2013. Além disso, ambos seriam convidados a elaborar grandes projetos públicos na Áustria, bem como projetos para compor a decoração do prédio da ONU, em Nova York.

25 Veja-se o catálogo da exposição Beck. São Paulo: Museu de Arte Moderna de São Paulo, julho de 1955.

26 Sobre Picasso e sua presença no meio artístico internacional, novamente com muita força, no segundo pós-guerra, também seria necessária uma revisão. Alguns artistas italianos do Fronte dell'Arte, que entre 1952 e 1954, dariam origem ao Gruppo degli Otto, teriam processado suas pesquisas de abstração no diálogo com a pintura de Picasso, a exemplo das duas grandes telas de Mattia Moreni, hoje no acervo do MAC USP, provenientes do ambiente da Bienal. Observe-se ainda que a apresentação de "Guernica" na II Bienal de São Paulo correspondia à etapa final de uma itinerância da obra por várias capitais europeias. Antes de chegar aqui, ela havia sido exibida nas grandes galerias do Palazzo Reale, em Milão (outubro a dezembro de 1953).

27 Essa noção seria retomada, pode-se dizer, por duas vias. Em primeiro lugar, no resgate da chamada arte do inconsciente e das experiências de artistas autodidatas; em segundo, pelo novo impulso da descoberta, no início dos anos 1940, das pinturas rupestres de Lascaux.

28 Para uma análise dessa política de afirmação cultural norte-americana, veja-se o já clássico estudo de Serge Guilbaut. How New York Stole The Idea Of Modern Art. Chicago:The University of Chicago Press, 1985. 
lemos nas histórias escritas sobre ela), a sala de Jackson Pollock na edição de 1957 como representação nacional norte-americana teria tido enorme reverberação no meio artístico local. No entanto, e apesar da política cultural hegemônica norte-americana nos anos da Guerra Fria (que muito contribuiu para a formação de nossas instituições de promoção de arte moderna), não foi isso que se colecionou no antigo MAM. Uma das poucas obras norte-americanas a dar entrada no acervo do antigo MAM, naqueles anos, como prêmio-aquisição é "OViking" de Ralph Du Casse. O artista, nascido em São Francisco, e professor da California School of Fine Arts, participou na representação nacional norte-americana de 1955. Esta delegação foi organizada, não pelo MoMA de Nova York, mas por duas importantes instituições da Costa Oeste dos Estados Unidos: o Museu de Arte Moderna de São Francisco (SFMoMA) e o Museu de Ciências, História e Artes de Los Angeles. Os diretores artísticos das respectivas instituições apresentaram uma enorme seleção de artistas dos maiores centros dos três estados banhados pelo Oceano Pacífico: uma exposição com dezenas de nomes nas categorias de pintura, escultura, gravura e desenho. $O$ texto de apresentação da comissária Grace McCann Morley, do SFMoMA, situou a representação territorialmente. Se nas primeiras edições da Bienal de São Paulo havia uma presença marcante da Costa Leste do País, e sobretudo do meio artístico de Nova York, nesta edição tratava-se de mostrar a força da arte da Costa Oeste, em centros como Los Angeles e São Francisco. Muitos dos artistas então exibidos - como o próprio Du Casse - tinham participado, um ano antes, numa mostra intitulada 57 Younger American Painters, no Museu Guggenheim de Nova York. E por mais que os jornais, principalmente os norte-americanos, procurassem assimilar esses artistas à experiência nova-iorquina do expressionismo abstrato, vemos que essas relações também eram bem mais complexas, e por vezes contestadas pelos artistas da Costa Oeste ${ }^{29}$.

Finalmente, seria preciso estudar a fundo os desdobramentos do tachismo e do informalismo no Brasil, a partir da presença dos artistas dessas vertentes nas edições da Bienal de São Paulo de sua primeira década de existência ${ }^{30}$.A celebração dessas práticas de abstração mais expressiva, não-geométrica, teve seu ponto alto na $V$ Bienal de São Paulo, em 1959, com a segunda direção artística de Lourival Gomes Machado - naquele momento, plenamente engajado no estudo desse fenômeno e suas articulações com o barroco ${ }^{31}$. Do conjunto

Veja-se também o célebre texto de Clement Greenberg, “'American-Type' Painting” In: Art and Culture. Critical Essays. Boston: Beacon Press, 1989, pp. 208-229. ( la. edição, 1961).

29 Que é o que o próprio Ralph Du Casse viria a fazer em entrevistas, quando era apontado como discípulo de Hans Hoffmann. Veja-se clipping da pasta do artista, Arquivo Histórico Wanda Svevo, Fundação Bienal de São Paulo.

30 O estudo dessas vertentes parece ter, na historiografia da arte no Brasil, maior corpo de reflexão no que diz respeito à gravura. Veja-se, por exemplo, a pesquisa de Maria Luíza Távora sobre a gravura brasileira nos anos 1950-60. ."Veja-se, por exemplo, Tavora, Maria Luisa Luz . A gravura abstrata de Fayga Ostrower e a primazia da cor no Informalismo no Brasil. In: Flora Sussekind;Tania Dias;Carlito Azevedo. (Org.). Vozes femininas: gênero, mediações e práticas de escrita. I ed.Rio de Janeiro: Ediçoes Casa de Rui Barbosa/ Editora 7 Letras, 2003, v. I, p. 238-246." 3I Veja-se Ana Cândida F. de Avelar Fernandes. "O informalismo no Brasil: Lourival Gomes Machado e a 5a. Bienal Internacional de São Paulo”, Atas do VII Encontro de História da Arte: Os Caminhos da História da Arte desde Giorgio Vasari: Consolidação e desenvolvimento da disciplina, Campinas, 20 I I. Disponível em: http://www.unicamp.br/chaa/eha/atas/20I I/Ana\%20Candida\%20F\%20 de\%20Avelar.pdf. $O$ texto resulta de tese de doutorado da autora, apresentada ao Departamen- 
incorporado como prêmio-aquisição da Bienal de São Paulo em sua primeira década de existência, inúmeros são os exemplos de artistas ligados a essas vertentes, fazendo com que os percursos do concretismo por via das obras reunidas dessa forma não parecessem tão evidentes ou bem-pavimentados. Já mencionamos anteriormente a pintura de Fritz Winter, interpretada na chave da arte abstrata geométrica/concreta. $O$ caso de Willi Baumeister, com seu "Gesto cósmico" (1950), lido também a partir dessas premissas, apela concomitantemente ao expressivo e gestual, com suas formas primitivas e sua superfície rudimentar - se assim podemos dizer. Do ponto de vista das práticas do informalismo, "Cabeça trágica" (1959) de Karel Appel ilustra bem a materialidade, a noção de gesto do artista, bem como propõe uma reavaliação da pintura como um ato primitivo.

Se a abstração é o grande debate em pauta nos anos 1950, ainda estamos por entender qual o papel da arte latino-americana nesse contexto.Através dos estudos dos grupos concretistas no Brasil - que parece andar emparelhado com a pesquisa das práticas concretistas realizada em outros países docontinente - foram se criando na última década alguns diálogos importantes ${ }^{32}$. No entanto, a revisão do informalismo no continente ainda é imperativo e resta por ser feito. Mas mais do que isso, é preciso avaliar a inexistência de um conjunto representativo de obras latino-americanas ${ }^{33}$. Apesar também de alguns exemplos pontuais, como das obras de Armando Morales e Rodolfo Abularach, não se pode dizer que o acervo modernista que ia se formando naqueles anos tinha uma presença importante de nomes latino-americanos. Talvez seja preciso avaliar esse aspecto à luz de um elemento importante do jogo diplomático do contexto da Guerra Fria. Na Bienal dos anos 1950, havia outra força hegemônica em ação, ela também engendrada pela política externa norte-americana: a União Panamericana, que organizou mostras de artistas latinoamericanos nas edições da Bienal de São Paulo. Com sede em Washington, seu objetivo era o de promover a arte latino-americana expondo artistas cujos países de origem não tinham possibilidade de financiar sua representação na Bienal de São Paulo ${ }^{34}$.Alguns prêmios da Bienal vêm dessas mostras especiais - como no caso de

to de Artes Visuais da ECA USP, em agosto de 2012, publicação no prelo.

32 Em particular no caso argentino, houve contribuições importantes para esses estudos comparativos a exemplo do volume organizado por Andrea Giunta e Laura Malosetti em torno da revista Ver y Estimar. Cf. Andrea Giunta e Laura Malosetti Costa (orgs.). Arte de posguerra. Jorge Romero brest y la revista Ver y Estimar. Buenos Aires: Editora Paidós, 2005, em especial os escritos de Cristina Rossi e Maria Amália García.

Em 2004, o Los Angeles County Museum of Art organizou uma grande mostra de revisão das vertentes concretistas no mundo, em que pela primeira vez, considerou-se as produções brasileira e latino-americana em diálogo com os centros europeus e com os Estados Unidos. Cf. Lynn Zelevansky. Beyond Geometry. Experiments in Form, 1940s-1970s. Cambridge, MA: MIT Press, 2004. E mais recentemente, cf. Mary Kate O'Hare (org.). Constructive Spirit:Abstract Art in South and North America, 1920s-50s. Nova York: Pomegranate, 2010, também catálogo de exposição organizada no Newark Museum. Por fim, o livro de Sérgio Martins, publicado nos Estados Unidos. Cf. Sérgio Martins. Constructing and Avant-Garde. Art in Brazil, 1949-1979. Cambridge, MA: MIT Press, 2013.

33 Quando diretora do MAC USP,Aracy Amaral tomou como ação prioritária a constituição para o Museu de um importante núcleo de artistas latinoamericanos, base de seu programa de aquisições e que não se realizou plenamente, uma vez que a USP jamais resolveu a questão dos fundos que deveriam ser destinados a uma política de aquisição - não só para o MAC, mas também para os demais museus da universidade. Cf. Aracy Amaral, “Do MAM ao MAC: História de uma Coleção" In: Textos do Trópico de Capricórnio:Artigos e Ensaios (1980-2005),Vol. 2: Circuitos de Arte na América Latina e no Brasil. São Paulo: Editora 34, pp. 238-279 (originalmente publicado em 1988).

34 A União Panamericana (ou a Secretaria Geral da Organização dos Estados Americanos - OEA, como 
Armando Morales -, mas sem efetivamente formar um conjunto coeso de obras latino-americanas para o acervo do antigo MAM.Ao mesmo tempo, continuam ausentes nomes como Wimfredo Lam, Xul Solar, Gego, Roberto Matta, Alberto Berni, José Clemente Orozco, Diego Rivera e Frida Kahlo, para citar apenas alguns dos maiores artistas do México à Argentina ${ }^{35}$.

Há um último elemento importante a se considerar, que diz respeito ao sistema da arte construído com a institucionalização da arte moderna. $O$ exercício de voltar às obras e aos artistas pontualmente foi nos revelando que a trajetória percorrida por eles passava pela sua promoção em seus territórios de origem, sua projeção internacional ainda dentro de um circuito de galerias parisienses, para que eles fossem, na ponta do processo, elevados à categoria de artistas internacionais no ambiente, primeiro, da Bienal de Veneza, para chegar à Bienal de São Paulo. O mesmo passa a ocorrer com os artistas brasileiros, que acabavam por fazer o caminho inverso - de exibir na Bienal de São Paulo para entrar no circuito internacional e conseguirem ser apresentados em grandes museus e galerias de Paris, Londres, Nova York, etc.

De fato, a narrativa de arte moderna que se construiu no ambiente da Bienal de São Paulo passa necessariamente por uma análise das relações diplomáticas e a dimensão política que iniciativas como essa da União Panamericana têm no contexto da Guerra Fria. Porém, e diante do fenômeno recente de globalização da arte contemporânea e do sistema das artes do Ocidente - cujo modelo vem sendo implantado com grande sucesso em realidades orientais tão díspares quanto a China, os países do Oriente Médio aliados à política norte-americana (como os Emirados Árabes Unidos), e a Coréia do Sul - a historiografia da arte vem se tornando mais atenta à constituição de uma narrativa-mestre da história da arte moderna, que implantada em novos territórios parece ter tido estreita relação com o sistema das Bienais de arte $^{36}$. Isto é, o exemplo paulista é hoje um caso privilegiado de estudos sobre a relação entre esse sistema internacional (e depois globalizado) das artes e a constituição de museus de arte no século $X X$.

ela passa a ser oficialmente chamada a partir de 1948) era um Órgão diretamente ligado ao Departamento de Estado norte-americano. Seu Departamento de Artes Visuais foi dirigido pelo crítico cubano radicado nos Estados Unidos, José Gomes Sicre, de 1948 a 1976. As atividades do Departamento de Artes Visuais e de Gomes Sicre dariam início ao Art Museum of the Americas, fundado em 1976, com sede em Washington. Para a atuação de José Gomes Sicre a sua atuação na União Panamericana, veja-se pesquisa ainda não publicada do doutorando Alessandro Armato, da Universidad de Buenos Aires. Armato, que foi pesquisador dentro do Programa Acervos da USP, com o apoio da Pró-Reitoria de Pesquisa da Universidade, em 20I3, chama a atenção para o fato de que Gomes Sicre teria tido, neste contexto, papel importante não só na consolidação de certa ideia da arte do continente, ao fomentar justamente as práticas mais ligadas a uma abstração não-geométrica e informal. Cf. Armato, Alessandro, 'Una trama escondida: la OEA y las participaciones latinoamericanas en las primeras cinco Bienales de São Paulo', Revista Caiana, no. 6, primer semestre 2015, pp. 33-43

35 Joaquín Torres-Garcia figura hoje no acervo do MAC USP com uma pintura de seu período parisiense, através do comodato (por decisão judicial) da Cid Collection (coleção Edemar Cid Ferreira, em depósito no Museu desde 2005) - portanto completamente fora do contexto que estamos tratando aqui.

36 Veja-se os textos de Hans Belting no contexto da plataforma criada pelo Zentrum für Kunst und Medientechnologie (ZKM), em Karlsruhe, Alemanha, aonde ele curou uma grande exposição sobre o fenômeno da globalização na arte contemporânea em 20II (The Global Contemporary. Kunstwelten nach 1989, ZKM?Museum für Neue Kunst, Karlsruhe, setembro de $201 \mathrm{I}$ a fevereiro de 2012, disponível em: http:// www.global-contemporary.de/). Cf. Hans Belting, "Contemporary Art and the Museum in the Global Age". In: Peter Weibel \& Andrea Buddensieg (orgs.). Contemporary Art and the Museum.A Global Perspective. Ostflidern: Hatje Cantz, 2007, pp. 16-4I; e Hans Belting, op.cit., 2009. 
Voltando à questão de um acervo datado de arte moderna, o antigo MAM incorporou ao seu acervo um conjunto de obras que relfetiam os debates da arte nos anos 1950, e não parece ter se preocupado com uma visão retrospectiva de seu acervo.Tal visão veio quando este foi transferido para a USP. Mas até então, a antigo MAM parecia estar constituindo um acervo do seu próprio tempo, em outras palavras, um acervo contemporâneo. Um exemplo notável é a ação de Matarazzo como presidente do antigo MAM, quando de sua ida à Bienal de Veneza em 1952. Além de adquirir o “Grande Cavalo" de Marino Marini, ele trouxe para o Brasil outras I 3 obras, oito das quais representavam justamente - Gruppo degli Otto, sob liderança do crítico e historiador da arte Lionello Venturi.Afro Basaldella, Giuseppe Santomaso, Renato Birolli, Mattia Moreni, Antonio Corpora, Ennio Morlotti e Emilio Vedova tornavam-se assim, no momento mesmo de sua afirmação, parte do acervo do antigo MAM.

A separação entre o antigo MAM e a Bienal de São Paulo em 1962, e a transferência de seu acervo para a USP em 1963, criando-se o MAC USP, certamente significou a ruptura entre um programa de aquisição via a premiação do evento Bienal e o acervo do Museu. Mesmo assim, e à revelia de uma discussão consciente do MAC USP sobre sua relações com o evento Bienal, algumas obras que participaram das edições do evento acabaram no acervo do Museu ao longo dos anos. De certo modo, essas ações pontuais pareciam ainda perceber o acervo do MAC USP como o lugar mais apropriado para a incorporação dessas obras. Mas a grande diferença entre colecionar no contexto da Bienal dos anos 1950 e depois disso, é o fato de que o MAC USP (assim como outros museus da cidade de São Paulo) parecem ter deixado de ter qualquer conexão com esse tipo de evento. Houve, nas edições de 2008,2010 e 2012 algumas tentativas de chamar os museus de arte moderna e contemporânea de São Paulo para criar um programa como de exposições durante o período de realização das Bienais. Levantou-se inclusive a possibilidade de dividir com os museus locais a seleção de artistas da Bienal para que os museus pudessem formular propostas de incorporação/aquisição de obras. A Bienal de São Paulo é sobretudo apoiada por recursos públicos - seja por via do Fundo Nacional de Cultura, seja por via dos patrocínios que chegam através da Lei de Incentivo Fiscal do Ministério da Cultura do Brasil. Seria assim bem-vinda a proposta de se formular uma política consistente de aquisição de artistas latino-americanos e estrangeiros em geral para os acervos dos museus locais no contexto da Bienal. Atualmente, museus públicos brasileiros estão praticamente impossibilitados de adquirir obras de artistas, dados seus orçamentos diminutos. Quando se trata de aquisição de obras do exterior, os museus locais são atropelados pelos processos de importação e suas altas taxações.

Finalmente, um fenômeno a ser estudado hoje, e que pode ser observado nos últimos anos, em comparação ao que tivemos nos anos 1950, é o fato do Brasil, e principalmente a cidade de São Paulo, abrigar coleções privadas importantes de arte contemporânea nacional e estrangeira, bem como ter assistido à expansão de sua feira de arte, a SP Arte. Ou seja, São Paulo parece ser um dos melhores lugares do mundo para ser um artista, começar uma coleção de arte e criar um museu de arte contemporânea. As grandes estrelas da arte internacional continuam a nos visitar e a propor novas obras para as edições da Bienal de São Paulo. Entretanto, nossas instituições históricas parecem não ter 
relevância nesse contexto. A grande maioria das obras, quando vendidas aqui, acabam em coleções privadas. Museus como o MAC USP tem de lutar com a burocracia e seu orçamento para manter o mesmo nível de aquisições de obras internacionais que seu acervo teve nos anos 1950. Há quatro anos, a SP Arte vem tentando estabelecer uma parceria com o Museu (assim como outros museus da cidade) para que possamos adquirir obras de arte para nossos acervos. Neste sistema de mecenato, os curadores do Museu escolhem obras exibidas na feira que são compradas por patrocinadores privados e doadas ao seu acervo. De certa maneira, ele parece substituir o velho sistema de prêmios-aquisição da Bienal, embora muito mais tímido e sem apoio de uma política pública efetiva. Num momento em que as feiras de arte também assistem a um enorme boom e se assemelham cada vez mais aos espaços institucionais de exibição da arte contemporânea, é lícito levantar a hipótese de que o sistema de internacionalização da linguagem artística colocado em funcionamento na década de 1950 parece hoje ganhar outras roupagens.

A pergunta que nos caberia fazer a partir de agora e diante do acervo histórico das obras oriundas do ambiente da Bienal de São Paulo em sua primeira década de existência é em que medida ele nos ajuda a entender o papel desse sistema na moldagem da história da arte moderna e como ele poderia nos orientar a ampliá-lo.

\section{REFERÊNCIAS}

ALAMBERT, Francisco \& CANHÊTE, Polyanna. As Bienais de São Paulo: Da Era do Museu à Era dos Curadores (195 I-200 I). São Paulo: Boitempo Editorial, 2004.

ALTSHULER, Bruce. Salon to Biennial. Exhibitions that Made Art History, I 863-I 959 (Vol. I). Londres: Phaidon Press, 2008.

AMARAL,Aracy, “Do MAM ao MAC: História de uma Coleção” In: Textos do Trópico de Capricórnio:Artigos e Ensaios ( 1980-2005),Vol. 2: Circuitos de Arte na América Latina e no Brasil. São Paulo: Editora 34, pp. 238-279.

ARGAN, Giulio Carlo. L'Arte Moderna: Dall'Illuminismo ai Movimenti Contemporanei. Florença: Sansoni Editori, 1970.

BELTING, Hans \& BUDDENSIEG, Andrea (orgs.). The Global Art World.Audiences, Markets, and Museums. Ostfildern: Hatje Cantz, 2009, pp. 38-73.

FERNANDES, Ana Cândida F. de Avelar, "O informalismo no Brasil: Lourival Gomes Machado e a 5a. Bienal Internacional de São Paulo", Atas do VII Encontro de História da Arte: Os Caminhos da História da Arte desde Giorgio Vasari: Consolidação e desenvolvimento da disciplina, Campinas, 20I I. Disponível em: http://www.unicamp.br/chaa/eha/atas/20I I/Ana\%20Candida\%20F\%20de\%20Avelar.pdf.

FRANCO, Maria Eugênia, "Importância educativa da exposição”, Reportagem I da série "Panorama da 2a. Bienal”, Última Hora, Io. de fevereiro de 1954.

GIUNTA, Andrea Giunta \& COSTA, Laura Malosetti (orgs.). Arte de posguerra. Jorge Romero brest y la revista Ver y Estimar. Buenos Aires: Editora Paidós, 2005.

GREENBERG, Clement,“'American-Type' Painting” In: Art and Culture. Critical Es- 
says. Boston: Beacon Press, 1989, pp. 208-229. ( la. edição, 196I).

GROOS, Ulrike \& PREUSS, Sebastien (orgs.). German Art in São Paulo. Ostfildern: Institut für Auslandsbeziungen/Hatje Cantz, 2013.

GUILBAUT, Serge. How New York Stole The Idea Of Modern Art. Chicago:The University of Chicago Press, 1985.

MACHADO, Lourival Gomes. “Apresentação” In: : I Bienal do Museu de Arte Moderna de São Paulo, outubro a novembro de 195I. São Paulo: Museu de Arte Moderna de São Paulo, I95I (vol. I).

MAGALHÃES, Ana Gonçalves, "O debate crítico na Exposição do Edifício Sul América, Rio de Janeiro, 1949" In: Roberto Conduru \& Vera Beatriz Siqueira (orgs.). Anais do XXIX Colóquio do Comitê Brasileiro de História da Arte. Rio de Janeiro: Comitê Brasileiro de História da Arte / CBHA, 2009, pp. I 20-I 28.

MARTINS, Sérgio. Constructing and Avant-Garde. Art in Brazil, 1949-1979. Cambridge, MA: MIT Press, 2013.

MENDES, Murilo, “Sugestões da Bienal”, Diário Carioca, 02/I2/I95 I.

MERKLINGER, Martina. Die Biennale São Paulo. Kulturaustausch zwischen Brasilien und der jungen Bundesrepublik Deutschland (1949-1954). Bielefeld:TranscriptVerlag, 2013.

. "Konkretes im Bill-Jahr. Max Bill (1908-1994) und seine Begegnungen mit Brasilien”, Martius-Staden Jahrbuch, n55, 2008.

O novo edificio Sul América Terrestres, Marítimos e Acidentes - Sucursal do Rio de Janeiro, 1949.

READ, Herbert. A Concise History of Modern Painting. Londres:Thames \& Hudson, 1959.

Revista da USP: Cinquenta Anos de Bienal Internacional de São Paulo, no. 52, dez/jan/ fev, 200I-2002.

SHARP, Jasper (org.). Österreich und die Biennale Venedig, I895-2013. Nuremberg:Verlag für Moderne Kunst, 20I3.

WEIBEL, Peter \& BUDEENSIEG, Andrea (orgs.). Contemporary Art and the Museum. A Global Perspective. Ostflidern: Hatje Cantz, 2007, pp. I6-4I.

\section{Catálogos de exposições}

Beck. São Paulo: Museu de Arte Moderna de São Paulo, julho de 1955.

Catálogo Exposição do Art Club de Roma, junho/julho de 1950, Museu de Arte Moderna de São Paulo.

Cat. Exp. Prêmios da Bienal de São Paulo. São Paulo: MAC USP, 1985.

Do figurativismo ao abstracionismo [textos de Sérgio Milliet e Léon Degand]. São Paulo: Museu de Arte Moderna, 1949.

O'HARE, Mary Kate (org.). Constructive Spirit: Abstract Art in South and North 
America, 1920s-50s. Nova York: Pomegranate, 2010.

ZELEVANSKY, Lynn. Beyond Geometry. Experiments in Form, 1940s-1970s. Cambridge, MA: MIT Press, 2004.

\section{Bienal de São Paulo}

I Bienal do Museu de Arte Moderna de São Paulo, outubro a novembro de 195 I. São Paulo: Museu de Arte Moderna de São Paulo, I95I (Ia. edição).

I Bienal do Museu de Arte Moderna de São Paulo, outubro a novembro de 195I. São Paulo: Museu de Arte Moderna de São Paulo, I95I (2a. edição).

Il Bienal do Museu de Arte Moderna de São Paulo. Catálogo geral. São Paulo: Museu de Arte Moderna de São Paulo, 1953.

III Bienal do Museu de Arte Moderna de São Paulo. Catálogo. São Paulo: Museu de Arte Moderna de São Paulo, 1955.

IV Bienal do Museu de Arte Moderna de São Paulo. Catálogo geral. São Paulo: Museu de Arte Moderna de São Paulo, 1957 ( Ia. edição).

IV Bienal do Museu de Arte Moderna de São Paulo. Catálogo geral. São Paulo: Museu de Arte Moderna de São Paulo, 1957 (2a. Edição).

V Bienal do Museu de Arte Moderna de São Paulo. Catálogo geral. São Paulo: Museu de Arte Moderna de São Paulo, 1959 (I a. edição).

V Bienal do Museu de Arte Moderna de São Paulo. Catálogo geral. São Paulo: Museu de Arte Moderna de São Paulo, 1959 (2a. Edição).

VI Bienal do Museu de Arte Moderna de São Paulo. Catálogo geral. São Paulo: Museu de Arte Moderna de São Paulo, I96I ( Ia. edição).

VI Bienal do Museu de Arte Moderna de São Paulo. Catálogo geral. São Paulo: Museu de Arte Moderna de São Paulo, I96I (2a. edição).

VII Bienal do Museu de Arte Moderna de São Paulo. Catálogo geral. São Paulo: Museu de Arte Moderna de São Paulo, 1963 ( I a. edição).

VII Bienal do Museu de Arte Moderna de São Paulo. Catálogo geral. São Paulo: Museu de Arte Moderna de São Paulo, I 963 (2a. Edição).

\section{Bienal de Veneza}

XXIV Biennale diVenezia.Veneza:Serenissima, 1948.

XXV Biennale di Venezia.Veneza:Alfieri, 1950.

XXVI Biennale diVenezia.Veneza:Alfieri, I 952.

\section{Arquivos e fundos pesquisados}

Arquivo do Belvedere,Viena

Archivio Storico delle Arti Contemporanee - ASAC, Veneza 
Arquivo Histórico Wanda Svevo - AHWS, Fundação Bienal de São Paulo Arquivo MAC USP

Seção de Catalogação MAC USP

Artigo recebido em fevereiro 20 I5. Aprovado em maio 2015 